\title{
Malaria Household Knowledge and Behavior in Equatorial Guinea: Lessons to Be Learned
}

Maria Romay-Barja ${ }^{1,2}$, Jorge Cano ${ }^{3,4}$, Jose Maria Ugarte ${ }^{3}$, Jesus Roche ${ }^{3}$, Gloria Nseng ${ }^{5}$, Matilde Riloha ${ }^{5}$, Agustin Benito ${ }^{1,2}$ and Estefania Custodio ${ }^{1,6 *}$

${ }^{1}$ Centro Nacional de Medicina Tropical, Instituto de Salud Carlos III, Madrid, Spain

${ }^{2}$ Red de Investigación Colaborativa en Enfermedades Tropicales, RICET, Madrid, Spain

${ }^{3}$ Centro de Referencia de Control de Endemias, Malabo, Equatorial Guinea

${ }^{4}$ Faculty of Infectious and Tropical Diseases, London School of Hygiene \& Tropical Medicine, London, United Kingdom

${ }^{5}$ Ministerio de Sanidad y Bienestar Social, Malabo, Equatorial Guinea

${ }^{6}$ European Commission, Joint Research Center, Italy

\begin{abstract}
Background: Malaria continues to be a major public health problem in Equatorial Guinea, despite the control efforts made since 1990s. Upcoming control interventions should incorporate the behavioral and social aspects of malaria, for which is essential to have base-line and context-specific information.
\end{abstract}

Methods: A retrospective study was carried out to analyze the major outcomes of three cross-sectional surveys on malaria-related knowledge and behavior, conducted in Equatorial Guinea in 1996, 2001 and 2007. Results were described using frequencies, and major outcomes were compared between regions through logistic regression analysis adjusting by socio-economic and individual-related factors.

Results: The knowledge towards malaria was overall better in 2001 than in 1996 in rural Bioko, and the attitudes and practices concerning malaria treatment and prevention were more correct in Bioko Island than in mainland Equatorial Guinea in 2001. Results in the 2007 survey, showed limited knowledge but appropriate practices related to the management of children with clinical malaria in Bata.

Conclusion: Equatorial Guinea is a small but heterogenic country, with population showing distinct perception of malaria and its public health impact across regions. National malaria control strategies should have this diversity into account and sensitization campaigns should be tailored to context-specific misconceptions and different epidemiological patterns identified.

Keywords: Malaria; Social; Behavior; Equatorial Guinea; Knowledge; Community awareness

\section{Introduction}

Equatorial Guinea is a small country located in the Gulf of Guinea and consisting of an insular region and a mainland region. The whole country is categorized as a malaria high transmission area, with more than 1 case per 1000 population, and more than $80 \%$ of the cases due to $P$. falciparum [1]. Nowadays malaria is the leading cause of morbidity and mortality among children under five years of age, regardless of the control efforts made since late 1990 [2].

In the African continent, the increasing efforts and investments in malaria have contributed to a substantial decrease in the incidence of clinical cases although the disease remains a major public health problem in the Sub-Saharan region [1]. The WHO world malaria report 2014 estimated that 198 million cases of malaria and around 600,000 deaths occurred globally, with Africa accounting for $90 \%$ of the deaths. Furthermore, and despite the progress, malaria remains a major killer of children, particularly in Sub-Saharan Africa, where it takes the life of a child every 2 minutes [3].

Over the last 20 years, a set of interventions have been put in place in Equatorial Guinea with a geographic imbalance and Bioko Island, the largest island of the insular region, has capitalized most of them. During the 1990 decade several strategies were implemented, although with limited scope and primarily targeting Bioko rural populations [47]. In 2004, a large-scale control programme, the Bioko Island Malaria Control Programme (BIMCP), was launched with the major goal of achieving the elimination of malaria transmission in the island [8-11].

Meanwhile, in the mainland region of Equatorial Guinea the first set of interventions did not start until 2001, even though large scale interventions began in 2007, with the implementation of a 5-year project, the Equatorial Guinea Malaria Control Initiative (EqGMCi) [10]. The EqGMCi was similar on its conception to the BIMCP although not all provinces were equally covered [11].

Despite all these efforts and programmes the most recent prevalence rates published for Bioko Island and the mainland region, 18\% (in 2014) [12], and 52\% (in 2011) [11] respectively, show how malaria remains a major health issue in Equatorial Guinea.

In the assessment of the potential ways of improving malaria control strategies, there is global agreement on the necessity of operational research that helps create context specific messages based in scientific evidence [13]. Furthermore, malaria control programs need to broaden the focus on the parasite and the mosquito vector to the social and behavioral factors associated with the disease. Malaria control efforts cannot longer afford to overlook the multidimensional human context

*Corresponding author: Estefania Custodio, Centro Nacional de Medicina Tropical, Instituto de Salud Carlos III, Madrid, Spain, Tel: +39 339864 7092; E-mail: estefania.custodio@jrc.ec.europa.eu

Received: September 02, 2016; Accepted: September 24, 2016; Published: October 01, 2016

Citation: Romay-Barja M, Cano J, Ugarte JM, Roche J, Nseng Gloria, et al. (2016) Malaria Household Knowledge and Behavior in Equatorial Guinea: Lessons to Be Learned. J Infect Dis Preve Med 4: 134. doi: 10.4172/2329-8731.1000134

Copyright: (c) 2016 Romay-Barja M, et al. This is an open-access article distributed under the terms of the Creative Commons Attribution License, which permits unrestricted use, distribution, and reproduction in any medium, provided the original author and source are credited. 
that creates and supports different notions related to malaria prevention and treatment [14].

Knowledge and behavior are considered to be among the principal factors that influence vulnerability to malaria at individual, household and community levels, affecting the exposure and progression of the disease [15]. There is ample evidence on how malaria knowledge and behavior of the community can modulate the efficacy of the strategies to be implemented, as misconceptions or inappropriate behavior can interfere with the effectiveness of control measures [16].

Many of the interventions carried out in Equatorial Guinea included elements of Information, Education and Communication (IEC), and several operational research studies on malaria knowledge attitudes and practices were in place, but the majority of them have never been analyzed or published.

The Ministry of Health $(\mathrm{MoH})$ in Equatorial Guinea is expected to include in its new long-term strategic plan to fight malaria 20162020 , now in process of elaboration, actions aiming at increasing social awareness towards malaria and to promote adequate community behaviors related to the disease. Assembling the knowledge resulted from previous socio-behavioral studies conducted in the country may contribute to the design and implementation of more effective malaria control and prevention strategies.

Here we present the results of three cross-sectional surveys, which aimed at assessing the household knowledge and behavior related to malaria in Equatorial Guinea. These surveys were conducted in 1996, 2001 and 2007 and covered diverse geographic areas of the country.

\section{Material and Methods}

\section{Study area and population}

Equatorial Guinea is located in the Gulf of Guinea, with a surface area of $28,051 \mathrm{~km}^{2}$ and a total estimated population of 720,000 [17]. Equatorial Guinea consists of two regions: a mainland region, which is bordering with Cameroon to the north and Gabon to the south and east, and an insular region consisting of two provinces, Bioko and Annobon Islands.

Bioko is the largest island and where is located the country's capital, Malabo. The mainland region, where the $75 \%$ of the nation's population lives, is divided into four provinces: Centro Sur, Kie-Ntem, Wele-Nzas and Litoral where Bata, the largest city of this region, is located. Bubi is the biggest ethnic group in Bioko Island while Fang is the predominant ethnic group in mainland region. Other groups like Combe and Anoboneses are also present in both regions.

The country's tropical climate creates an ideal setting for transmission of malaria and as such, malaria is endemic with yearround transmission in the mainland and the islands [18].

The World Bank classified Equatorial Guinea as a high income country due to the benefits of its large off-shore oil reserves, exploited extensively since 1997, which resulted in a gross national income per capita of US\$13,560 in 2012 [19]. However, despite extensive infrastructure investments in recent years, Equatorial Guinea is still ranked 144 in the 2014 United Nations Human Development Index [20].

\section{Data collection}

This study analyses the results of three cross-sectional household surveys on malaria knowledge and behavior conducted in Bioko Island and mainland Equatorial Guinea between 1996 and 2007. Table 1 details the core characteristics of the surveys: region, area, date, sampling design, and number of households surveyed.

A first survey was conducted in rural communities of Bioko Island in May-August 1996. A random selection of 363 households from 30 communities was made from a census of rural communities where every household was identified by a single code associated with the head of household and respondents were adults of the household.

A second cross-sectional survey was carried out in 2001, targeting rural and urban communities and stratified by region; Bioko Island (October-November 2001) and mainland region (August-October 2001). For this survey, 477 households in 60 communities were randomly selected based on the II Population and Households Census 1994 [21], and respondents were adults present in the household at the time of the survey.

Finally, a third cross-sectional survey was undertaken in Bata (the largest city in mainland Equatorial Guinea) and surroundings, in MayJuly 2007. A simple random sample of 475 households was selected from a list of under- 5 year old children registered within the influence area of a health center (La Libertad Health Center). This health center covered the primary health care of northern urban neighborhoods of Bata and nearby villages of the coastal area. Respondents of the 2007 survey were the caregivers of the selected children.

Age and sex of the interviewees as well as information on the household ownership of radio and/or TV, as indirect measures of socioeconomic status, were collected in all three surveys. In the 1996 and 2001 surveys the level of studies attained by the respondents was also recorded as well as the average wake-up and bed- times for adults and children.

Data of three surveys were collected through semi-structured questionnaires by local trained personal. The questions focused on topics such as malaria transmission, malaria clinic and treatment, prevention and community control. The questionnaires were coincident in the main questions and these are analyzed in this study.

In the first two surveys (1996 and 2001) the adults interviewed were questioned about their malaria clinic and treatment history, while in the survey conducted in Bata in 2007 these questions specifically targeted the children under their care.

\section{Data processing and statistical analysis}

Common questions to the three surveys were analyzed, and grouped by subject category as described in Figure 1. The answers on drugs intake were classified into the following broad categories: antimalarial, antipyretic, traditional medicine, vitamins and antibiotics.

The number of real answers for each of the questions analyzed in the 1996 and 2007 surveys was computed and percentages calculated based on these absolute frequencies (i.e. excluding missing).

The 2001 survey was designed to enable regional comparisons. Percentages were then used to summarize samples characteristics, and differences between regions were assessed by the Rao-Scott adjusted Chi-square test. The differences in responses between regions were assessed by logistic regression, with each of the outcome variables as the dependent variable and the region of study as the independent one. In order to account for the socio-demographic differences between regions, and only for the most relevant questions (Table 1) we further performed a multivariable logistic regression model including as 

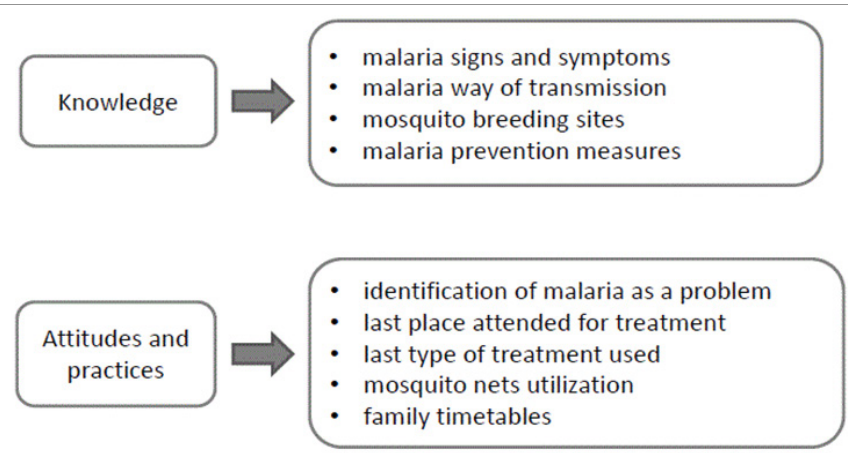

Figure 1: Subject Categories.

confounding variables the area of study (rural/urban), the sex and age of the interviewee, and the presence of radio and TV in the household (both introduced in the model independent of each other).

The adjusted odds ratios (AOR) and 95\% confidence intervals (95\% $\mathrm{CI})$ were computed for the multivariable models.

P-values less than or equal to 0.05 were considered statistically significant for all statistical analysis.

Data analysis was performed using SPSS version 18.0 (SPSS Inc., Chicago, Illinois, USA).

\section{Ethics, consent and permission}

The Ministry of Health and Social Welfare of Equatorial Guinea approved all three studies and questionnaires. Oral informed consent for participating in the study was obtained from all the interviewees.

\section{Results}

\section{Bioko Island (1996)}

In the 1996 survey, around $58 \%$ of the individuals selected among the rural households were women. Overall, $18 \%$ of the respondents had reached secondary education, and $37 \%$ reported to have radio in the house.

More than $90 \%$ of respondents identified "Fever" as a major symptom of malaria infection. Among the interviewees, "Mosquito bites" (89\%) and the intake of some drinks (62\%) and foods (26\%) were reported the major causes of malaria. "Mosquito nets" was the most mentioned method for preventing malaria among the individuals interviewed (34\%).

Malaria was perceived as a "Problem" and classified as a "Health problem" by the majority of the respondents. Nearly $38 \%$ of the interviewee stated to have selected a health facility to treat their last malaria episode, although antimalarial drugs were reported as the treatment of choice by over $80 \%$ of them.

Mosquito nets were used by less than $40 \%$ of the population, and individuals pointed to the unavailability of bed nets as the main reason for not using them. Other frequent responses were that they were "too hot", or "insufficient number of bed nets to protect all members of the family."

\section{Bioko Island and mainland region in 2001}

In the 2001 survey, the majority of the respondents in Bioko Island were women while in the mainland region $51 \%$ were males. The Bioko respondents were also younger, had a higher educational level, and more access to TV and radio at home as compared to the mainland sample (Table 2).

Over $92 \%$ of the respondents in 2001 identified fever as a malariarelated symptom and mosquito bites as a cause of malaria transmission, and responses associating malaria transmission with drinks and foods were over $70 \%$ and $50 \%$ respectively, in both regions. The majority in both regions also associated water and puddles with mosquito breeding sites and pointed the mosquito nets as one of the best method of prevention (Table 3 ).

The perception of malaria as a 'problem' was eight times higher in Bioko and the use of "Antimalarial" drugs was also more frequently reported (85.1\%) in Bioko than in the mainland region (65.4\%), while the use of "Traditional medicine" was less reported in the island. However, the attendance to health facilities for malaria treatment was around $60 \%$ for both regions in this survey (Table 4 ).

The average wake-up time for adult and children was around 6.30 am and average bedtime around $8.30 \mathrm{pm}$ for children and $9.30 \mathrm{pm}$ for adults. These values did not show any change for the regions and years analyzed.

\section{Bata (mainland region)}

Respondents of the 2007 survey in Bata were mostly female, with a mean age of 28 years (standard deviation (SD): 9.9). Nearly $80 \%$ of them said to have a radio and/or a TV at home.

Most of the respondents identified fever (93.9\%) and weakness (89.2\%) as malaria-related symptoms. However, mosquito bite, as a way of transmission, was reported only by $68.1 \%$ of the respondents, and mosquito nets as a prevention measure by $66.2 \%$.

More than $90 \%$ of the caregivers considered malaria a serious problem for the community, and $70 \%$ of them declared having taken their children to a health facility for seeking malaria treatment. Over 96\% said to have used "Antimalarial" drugs and "Antipyretic" as the first treatment of choice to treat the latest malaria episode of the children in their care.

Finally, 75.3\% of children were reported to have slept under a bed net the night before to the survey.

\section{Discussion}

This study analyses the malaria household knowledge and behavior of three surveys conducted in 1996, 2001 and 2007, in different geographic areas of Equatorial Guinea. The outcomes of these three cross-sectional surveys suggest that the knowledge towards malaria in rural Bioko in 1996 was quite appropriate but not the main practices related to treatment and prevention. In year 2001, the knowledge, attitudes and practices in general seems more correct in Bioko Island than in mainland region. Results in the 2007 survey, showed limited knowledge but appropriate practices related to the management of children with clinical malaria in an area of the capital of the continental region (Bata).

These differences in household knowledge and behaviour might be at some extent related to the imbalance by regions of the interventions implemented in the country at the time the surveys were conducted. Thus, appropriate knowledge regarding malaria signs, symptoms and transmission was high (above $90 \%$ of correct responses) in the three surveys, but highest in Bioko Island in 2001 where more control interventions against malaria have been implemented since early 1990s. This may be among the underlying reasons for the good social 
Citation: Romay-Barja M, Cano J, Ugarte JM, Roche J, Nseng Gloria, et al. (2016) Malaria Household Knowledge and Behavior in Equatorial Guinea: Lessons to Be Learned. J Infect Dis Preve Med 4: 134. doi: 10.4172/2329-8731.1000134

Page 4 of 7

\begin{tabular}{|c|c|c|c|c|}
\hline Region & Year & Area & Sampling design \\
\hline Bioko Island & 1996 & Rural & Multistage random selection \\
\hline Bioko Island & 2001 & Urban/Rural & Multistage random selection \\
\hline Continental Region & & Bata Area* & Simple stage random selection \\
\hline Continental Region & 2007 & (r) & 208 \\
\hline *Health Area of La Libertad Health Center (rural villages and urban neighborhoods) & \\
\hline
\end{tabular}

Table 1: Characteristics of the cross-sectional KAP surveys.

\begin{tabular}{|c|c|c|c|c|c|}
\hline \multirow{4}{*}{ Variables } & Bioko Island & \multicolumn{3}{|c|}{ Bioko Island and Continental Region } & \multirow{2}{*}{$\begin{array}{c}\text { Continental Region } \\
\text { Bata City } 2007\end{array}$} \\
\hline & 1996 & $\begin{array}{l}\text { Bioko Island } \\
2001 \text { All }\end{array}$ & Continental Region 2001 & \multirow{3}{*}{$\mathrm{p}$} & \\
\hline & $N=363$ & $\mathrm{~N}=269$ & $N=208$ & & $\mathrm{~N}=475$ \\
\hline & $\%$ & $\%$ & $\%$ & & $\%$ \\
\hline \multicolumn{6}{|l|}{ Area } \\
\hline Urban & 0.0 & 63.2 & 33.7 & \multirow{2}{*}{ ** } & 97.3 \\
\hline Rural & 100.0 & 36.8 & 66.3 & & 2.7 \\
\hline \multicolumn{6}{|c|}{ Sex } \\
\hline Female & 57.8 & 97.0 & 49.0 & \multirow{2}{*}{ ** } & 93.7 \\
\hline Male & 42.1 & 3.0 & 50.9 & & 6.3 \\
\hline \multicolumn{6}{|c|}{ Age Group(Years) } \\
\hline $15-25$ & 13.5 & 43.5 & 7.2 & \multirow{4}{*}{$\begin{array}{l}\text { ** } \\
* \star \\
* \\
* \star\end{array}$} & 49.4 \\
\hline $26-35$ & 21.5 & 36.8 & 38.5 & & 29.1 \\
\hline $36-45$ & 27.1 & 17.1 & 26.9 & & 14.9 \\
\hline$>46$ & 37.8 & 2.6 & 27.4 & & 6.6 \\
\hline \multicolumn{6}{|c|}{ Educational Level Attained } \\
\hline Primary School of - & 82.5 & 35.7 & 62.3 & \multirow{2}{*}{ ** } & - \\
\hline Secondary School or+ & 17.5 & 64.3 & 37.7 & & - \\
\hline \multicolumn{6}{|c|}{ Radio In House } \\
\hline No & 63.3 & 28.6 & 35.1 & & 22.5 \\
\hline Yes & 36.7 & 71.4 & 64.9 & & 77.5 \\
\hline \multicolumn{6}{|c|}{ Television In House } \\
\hline No & - & 42.4 & 93.3 & \multirow{2}{*}{ ** } & 14.6 \\
\hline Yes & - & 57.6 & 6.7 & & 85.4 \\
\hline
\end{tabular}

Table 2: Sample characteristics by year and region

acceptance of the BIMC Programme launched in 2004 and its rapid malaria prevalence reduction in the first two years [22], and it is consistent with observations in other endemic areas of Africa [23-26].

Unfortunately, knowledge on malaria-related morbidity, transmission and control measures seems to have decreased recently in Bioko Island according to a study conducted in 2009, where only $65 \%$ of the respondents recognized fever as a malaria symptom and $55 \%$ identified bed nets as a preventive measure of malaria [27]. This might be partially explained by a decline on the perception of malaria risk among the population due to the dramatic reduction of malaria prevalence in the island [28]. Other factors that could be related to this phenomenon are the intense demographic transitions experienced in the island, and the huge migration pressure from neighbouring countries and mainland Equatorial Guinea. It is important to maintain the sensitization and education of target groups during the life of the control projects and beyond, and to develop mechanisms that oversight the impact of such interventions on people's knowledge and social acceptability of the interventions.

The association of malaria transmission with food or beverages intake was surprisingly consistent in the three surveys studied and coincident with what has been reported in other areas [29]. These misconceptions should be further explored to be taken into account in future IEC interventions in Equatorial Guinea.

The overall lower knowledge registered in Bata in 2007, even though they were under the area of influence of a health centre, showed how the understanding of malaria could vary from community to community [30]. Health education interventions should be designed according to the existing knowledge and adapted to each region.

The perception of malaria as a community problem was very high across the three surveys compared to what it has been reported in other places in Africa where malaria is perceived as a relatively minor problem and health is far down on community main concerns [31]. These levels of household awareness are important in order to have a positive attitude towards the prevention of the disease. It would be necessary to study the actual perception of malaria in the different regions of the country for the design of future interventions.

Regarding treatment-seeking behaviour, our results show that home treatment was the main option only in rural Bioko in 1996. In the other surveys, health services were the preferably places to treat 
Citation: Romay-Barja M, Cano J, Ugarte JM, Roche J, Nseng Gloria, et al. (2016) Malaria Household Knowledge and Behavior in Equatorial Guinea: Lessons to Be Learned. J Infect Dis Preve Med 4: 134. doi: 10.4172/2329-8731.1000134

Page 5 of 7

\begin{tabular}{|c|c|c|c|c|c|c|c|c|c|}
\hline \multirow{4}{*}{ Variables } & \multirow{3}{*}{\multicolumn{2}{|c|}{$\begin{array}{c}\text { Bioko Island } \\
\begin{array}{c}1996 \text { Rural } \\
\mathrm{N}=363\end{array}\end{array}$}} & \multicolumn{6}{|c|}{ Bioko Island and Continental Region } & \multirow{3}{*}{$\begin{array}{c}\text { Continental Region } \\
\text { Bata Area } 2007 \\
\mathrm{~N}=475\end{array}$} \\
\hline & & & \multirow{2}{*}{\multicolumn{2}{|c|}{$\begin{array}{c}\text { Bioko Island } \\
2001 \text { All } \\
\text { N=269 }\end{array}$}} & \multirow{2}{*}{\multicolumn{2}{|c|}{$\begin{array}{c}\text { Continental Region } \\
\qquad 2001 \\
\mathrm{~N}=208\end{array}$}} & \multicolumn{2}{|c|}{ Bioko Island versus Continental Region } & \\
\hline & & & & & & & \multirow{2}{*}{$\mathrm{p}$} & \multirow{2}{*}{$\mathrm{AOR}(95 \% \mathrm{Cl}) \pm$} & \\
\hline & & $\%$ Yes & $\mathrm{n}^{8}$ & $\%$ Yes & & $\%$ Yes & & & $\mathrm{n}^{\&} \quad \%$ Yes \\
\hline \multicolumn{10}{|c|}{ Signs \& Symptoms } \\
\hline Fever & 347 & 90.5 & 268 & 96.6 & 208 & 94.2 & \multirow[t]{2}{*}{ * } & \multirow{6}{*}{$3.1(0.8-11.0)$} & 44193.9 \\
\hline Headache/Nausea & 347 & 90.5 & 267 & 97.0 & 208 & 97.6 & & & $354 \quad 77.7$ \\
\hline Weakness & 347 & 90.5 & 268 & 99.6 & 206 & 93.7 & \multirow[t]{2}{*}{ * } & & $397 \quad 89.2$ \\
\hline Itching & 347 & 90.5 & 260 & 56.5 & 208 & 94.4 & & & $226 \quad 27.4$ \\
\hline Cough & & - & 257 & 61.5 & 206 & 51.0 & * & & $359 \quad 81.9$ \\
\hline Pain to Urinate & & - & 259 & 52.1 & 202 & 32.2 & & & $221 \quad 18.5$ \\
\hline \multicolumn{10}{|c|}{ Malaria Transmission } \\
\hline It's caused by mosquito bites & 296 & 88.5 & 268 & 98.9 & 206 & 92.2 & * & \multirow{2}{*}{$3.1(0.7-14.0)$} & $367 \quad 68.1$ \\
\hline It's caused by some drinks & 329 & 61.7 & 263 & 70.0 & 201 & 72.6 & * & & $300 \quad 43.0$ \\
\hline It's caused by some food & 328 & 25.6 & 259 & 56.4 & 202 & 54.5 & * & & $297 \quad 40.7$ \\
\hline \multicolumn{10}{|c|}{ Mosquito breeding sites } \\
\hline Water/Puddles & 316 & 67.4 & 268 & 96.6 & 186 & 93.5 & & \multirow{4}{*}{$1.8(0.8-6.0)$} & $347 \quad 62.5$ \\
\hline Grass & 316 & 44.0 & 267 & 100.0 & 207 & 98.1 & * & & $117 \quad 3.4$ \\
\hline Forest & 316 & 0.6 & 256 & 44.1 & 204 & 56.9 & * & & $280 \quad 40.7$ \\
\hline Rubbish/dirtiness & 316 & 40.3 & 267 & 97.4 & 206 & 96.6 & * & & 11747.9 \\
\hline \multicolumn{10}{|c|}{ Mosquito prevention measures } \\
\hline Mosquito bed nets & 294 & 34.0 & 255 & 98.4 & 205 & 94.1 & * & \multirow{3}{*}{$2.3(0.5-9.6)$} & $370 \quad 66.2$ \\
\hline Making smoke & 294 & 24.5 & 268 & 95.5 & 208 & 74.0 & * & & - \\
\hline Cleaning the house & 294 & 12.2 & 247 & 95.5 & 208 & 94.7 & * & & - \\
\hline
\end{tabular}

Table 3: Crude and adjusted analysis of knowledge towards malaria by region in year 2001

\begin{tabular}{|c|c|c|c|c|c|c|c|c|c|c|}
\hline \multirow{4}{*}{ Variables } & \multirow{3}{*}{\multicolumn{2}{|c|}{$\begin{array}{c}\text { Bioko Island } \\
1996 \\
\mathrm{~N}=363\end{array}$}} & \multicolumn{6}{|c|}{ Bioko Island and Continental Region } & \multirow{2}{*}{\multicolumn{2}{|c|}{$\begin{array}{c}\text { Continental Region } \\
\text { Bata Area } 2007\end{array}$}} \\
\hline & & & \multirow{2}{*}{\multicolumn{2}{|c|}{$\begin{array}{c}\text { Bioko Island } \\
2001 \\
N=269\end{array}$}} & \multirow{2}{*}{\multicolumn{2}{|c|}{$\begin{array}{l}\text { Continental Region } \\
\qquad \begin{array}{c}2001 \\
N=208\end{array}\end{array}$}} & \multicolumn{2}{|c|}{$\begin{array}{c}\text { Bioko Island versus Continental } \\
\text { Region }\end{array}$} & & \\
\hline & & & & & & & \multirow{2}{*}{$\mathrm{p}$} & \multirow{2}{*}{$\operatorname{AOR}(95 \% \mathrm{Cl}) \pm$} & \multicolumn{2}{|c|}{$\mathrm{N}=475$} \\
\hline & & $\%$ Yes & & $\%$ Yes & & $\%$ Yes & & & $\mathrm{n}^{\&} \quad \%$ & $\%$ Yes \\
\hline \multicolumn{11}{|c|}{ Attitude towards malaria } \\
\hline Malaria is a problem & 352 & 96.0 & 269 & 99.3 & 208 & 95.7 & * & $8.1(1.0-63.9)$ & 410 & 95.2 \\
\hline \multicolumn{11}{|c|}{ Type of problem } \\
\hline A health problem & 321 & 77.6 & 269 & 87.0 & 208 & 90.9 & * & \multirow{3}{*}{$0.7(0.3-1.5)$} & 426 & 92.5 \\
\hline An economic problem & 321 & 13.4 & 269 & 29.7 & 208 & 39.9 & * & & 380 & 70.0 \\
\hline A social problem & 321 & 8.1 & 269 & 9.7 & 202 & 2.9 & * & & 389 & 74.0 \\
\hline \multicolumn{11}{|c|}{ Last place of treatment } \\
\hline Home/Pharmacy & 331 & 50.2 & 269 & 28.3 & 208 & 36.5 & * & \multirow{3}{*}{$1.7(1.0-2.9)$} & 278 & 48.2 \\
\hline Dispensary/Hospital & 331 & 57.5 & 269 & 65.4 & 208 & 59.1 & & & 342 & 70.2 \\
\hline Traditional healer & 331 & 7.6 & 269 & 0.7 & 208 & 3.4 & * & & 208 & 2.9 \\
\hline \multicolumn{11}{|c|}{ Last type of treatment } \\
\hline Antimalarial & 324 & 80.2 & 269 & 85.1 & 208 & 65.4 & * & \multirow[t]{3}{*}{$2.7(1.5-5.1)$} & 85 & 96.5 \\
\hline Antipyretic & 324 & 21.6 & 269 & 48.7 & 208 & 54.3 & * & & 157 & 98.7 \\
\hline Traditional medicine & 324 & 17.0 & 269 & 3.3 & 208 & 26.4 & * & & 157 & 0.6 \\
\hline Vitamins & 324 & 2.2 & 269 & 36.1 & 208 & 20.7 & * & & \multicolumn{2}{|r|}{ - } \\
\hline Antibiotics & 324 & 0.6 & 269 & 2.2 & 208 & 3.4 & * & & \multicolumn{2}{|c|}{ - } \\
\hline \multicolumn{11}{|c|}{ Using Mosquito nets } \\
\hline Yes & 363 & 29.2 & 269 & 41.3 & 208 & 26.4 & * & $1.0(0.6-1.7)$ & 442 & 75.3 \\
\hline
\end{tabular}

Table 4: Crude and adjusted analysis of attitudes and practices to treat and prevent malaria by region in year 2001 
malaria morbidity. This finding contrasts with the observed in most sub-Saharan African countries, where treatment is mostly sought out of the public health services $[24,25,32,33]$. However, in a recent survey conducted in rural and urban communities of Bata district, a $75.2 \%$ of caretakers also reported to have sought malaria treatment for their children in a health service [34].

The preference for health facilities was also accompanied by a high reported use of antimalarial drugs in both regions and for all periods. The lower utilization of traditional medicine reported in Bioko Island in 2001 may be associated with the population awareness promoted by IEC campaigns conducted within the project initiatives at that time [6]. A reduction in reliance on traditional remedies due to enhanced population knowledge on malaria causes and treatment has recently been described in Nigeria [35]. However, in the mainland region, the $26 \%$ use of traditional medicine reported in 2001 would be suggesting different treatment preferences in this region. A recent study conducted in Bata district in 2013 showed a similar pattern [34] as well as the existence of other factors that may contribute to the still high prevalence of malaria in the area despite these apparent appropriate behaviours. This study showed a median delay in seeking care for children of 2.8 days. Being treated at home first and the socioeconomic level of the household were determinants of this delay [36].

The reported use of mosquito nets by adults was below $42 \%$ in Bioko Island in 1996 and 2001, lower than the reported frequency in neighbouring countries [23], but consistent with the $41 \%$ reported in 2004 [37]. Inaccessibility to cost-free bed nets was reportedly the main reason given for not using them in our surveys. In Bioko Island, the ownership of bed nets increased to $97 \%$ in 2008 , thanks to scaling-up distribution of insecticide treated nets (ITNs) by BIMCP initiative, but abruptly dropped to $65 \%$ in 2009 [27]. Cost-free, or partially subsidized, access to ITNs has been recognised essential to tackle malaria $[22,35,38]$ and should be taken into account in the implementation of future strategies accompanied by sensitization campaigns to ensure regular and proper use of them.

In the survey conducted in Bata city, the reported use of mosquito nets in children was over $70 \%$, contrasting with the findings of the aforementioned study conducted in 2009 in the mainland region, in which only $26 \%$ of children under five were documented to have slept the previous night under a bed net [11]. This might be due to the fact that the 2007 survey was conducted in an area where bed nets distribution and awareness campaigns was recently carried out, reinforcing the importance of ensuring free access to ITNs.

According to the reported wake-up and bedtime habits, we could conclude that despite mass introduction of individual (e.g. ITNs) and community protective measures (e.g. indoor residual spraying, IRS), population could still be highly exposed to mosquito bites due to these habits, as malaria mosquitoes in Bioko exhibit an early evening indoor biting pattern with a peak time of activity at midnight [5]. This exposition risk may be becoming even higher over the last few years, after a study has shown an adaptive shift toward outdoor host seeking in Anopheles gambiae s.s. populations in some areas of Bioko Island. Moreover, diverse local habits could expose population to mosquito bites differently, as was shown in some vacation areas and Combe communities of Bioko Island [38].

We must acknowledge some limitations to this work. The cross-sectional design of the surveys does not allow for a causality assessment and, therefore, conclusions presented here are just the most plausible hypothesis, according to our knowledge and related to the control strategies implemented towards malaria in Equatorial Guinea at that time.

\section{Conclusions}

Equatorial Guinea is a small but heterogenic country, with population showing distinct knowledge and perception towards malaria prevention across regions. Control initiatives in Equatorial Guinea should account for the socio-geographic and economic differences between Bioko Island and mainland Equatorial Guinea, as well as their past history in malaria control interventions that may have resulted in a regional imbalance in malaria related knowledge and behaviors.

We identified consistent and context-specific misconceptions related to the disease that should be updated by forthcoming research and be addressed in future IEC activities.

Concerted efforts are still needed to scale-up protective measures at national level as well as to maintain a high level of social awareness of the risk of malaria over time.

Finally, the IEC campaigns to be designed and implemented in the coming years should be tailored to the different epidemiological contexts currently existing within the country.

\section{Competing Interest}

The authors have declared that they have no competing interest.

\section{Authors' Contributions}

MRB, EC conceived and designed the analysis of the data. JC, JMU, JR designed, coordinated and carried out the surveys. GN Coordinated the EG Malaria Programmes and participate in surveys' coordination. AB participated in surveys' coordination and reviewed the manuscript. MRB performed the data analyses and wrote the manuscript. EC participated in the data analysis. JC, EC reviewed and corrected the manuscript. All authors have read and approved the final manuscript.

\section{Acknowledgements}

The authors thank the study participants for volunteering, the data collectors for the fieldwork efforts, and the MoHSW of Equatorial Guinea. This study was funded by the Spanish International Cooperation Agency for Development (AECID) and the VI PN I+D+I 2008-2011 (National Plan of Research +Development +Innovation) of the Institute of Health Carlos III, ISCIII through its RETICs program (RICET-RD12/0018/0001)

\section{References}

1. WHO (2015) World malaria report 2015. Geneva.

2. WHO (2014) World Health Statistics. Geneva

3. Bhatt S, Weiss DJ, Cameron E, Bisanzio D, Mappin B, et al. (2015) The effect of malaria control on Plasmodium falciparum in Africa between 2000 and 2015. Nature 526: 207-211.

4. Roche J, Benito A, Ayecaba S, Amela C, Molina R, et al. (1993) Resistance of Plasmodium falciparum to antimalarial drugs in Equatorial Guinea. Ann Trop Med Parasitol 87: 443-449.

5. Cano J, Berzosa PJ, Roche J, Rubio JM, Moyano E et al. (2004) Malaria vectors in the Bioko Island (Equatorial Guinea): estimation of vector dynamics and transmission intensities. J Med Entomol 41: 158-161.

6. Molina R, Benito A, Roche J, Blanca F, Amela C, et al. (1993) Baseline entomological data for a pilot malaria control program in Equatorial Guinea. J Med Entomol 30: 622-624.

7. Roche J, Guerra-Neira A, Raso J, Benito A (2003) Surveillance of in Vivo Resistance of Plasmodium Falciparum to Antimalarial Drugs from 1992 to 1999 in Malabo (equatorial Guinea). Am J Trop Med Hyg 68: 598-601.

8. Kleinschmidt I, Sharp B, Benavente LE, Schwabe C, Torrez M, et al. (2006) Reduction in infection with plasmodium falciparum one year after the introduction of malaria control interventions on Bioko Island, Equatorial Guinea. Am J Trop Med Hyg 74: 972-978. 
Citation: Romay-Barja M, Cano J, Ugarte JM, Roche J, Nseng Gloria, et al. (2016) Malaria Household Knowledge and Behavior in Equatorial Guinea: Lessons to Be Learned. J Infect Dis Preve Med 4: 134. doi: 10.4172/2329-8731.1000134

9. Kleinschmidt I, Schwabe C, Shiva M, Segura JL, Sima V, et al. (2009) Combining Indoor Residual Spraying and Insecticide-Treated Net Interventions. Am J Trop Med Hyg 81: 519-524.

10. Rehman AM, Coleman M, Schwabe C, Baltazar G, Matias A, et al. (2011) How Much Does Malaria Vector Control Quality Matter: The Epidemiological Impact of Holed Nets and Inadequate Indoor Residual Spraying. PLoS ONE 6:e19205.

11. Rehman AM, Mann AG, Schwabe C, Reddy MR, Roncon Gomes I, et al. (2013) Five years of malaria control in the continental region, Equatorial Guinea. Malar J 12: 154.

12. Bradley J, Monti F, Rehman AM, Schwabe C, Vargas D, et al. (2015) Infection importation: a key challenge to malaria elimination on Bioko Island, Equatorial Guinea. Malar J 14: 46.

13. Guyant P, Corbel V, Guérin PJ, Lautissier A, Nosten F et al. (2015) Past and new challenges for malaria control and elimination: the role of operational research for innovation in designing interventions. Malar J 14: 279.

14. Dlamini SV, Liao C-W, Dlamini ZH, Siphepho JS, Cheng P-C, et al. (2015) Knowledge of human social and behavioral factors essential for the success of community malaria control intervention programs: The case of Lomahasha in Swaziland. J Microbiol Immunol Infect s1684.

15. Bates I, Fenton C, Gruber J, Lalloo D, Lara AM, et al. (2004) Vulnerability to malaria, tuberculosis, and HIVIAIDS infection and disease. Part 1: determinants operating at individual and household level. Lancet Infect Dis 4: 267-277.

16. Heggenhougen HK, Hackethal V, Vivek P (2009) The Behaviour and social aspects of malaria and its control: an introduction and annotated bibliography. Geneva

17. UNdata (2014) | country profile | Equatorial Guinea

18. Guerra-Neira A, Rubio JM, Royo JR, Ortega JC, Auñón AS, et al. (2006) Plasmodium diversity in non-malaria individuals from the Bioko Island in Equatorial Guinea (West Central-Africa). Int J Health Geogr 5: 27.

19. World Bank (2014) Equatorial Guinea | Data

20. Human Development Report Media Package (2014) Human Development Reports

21. Departamento de Estadística de la República de Guinea Ecuatorial.Ministerio de Planificación y Desarrollo Económico; 1997. II Censo de Población y Vivienda 1994. Guinea Ecuatorial.

22. Kleinschmidt I, Schwabe C, Benavente L, Torrez M, Ridl FC, et al. (2009) Marked Increase in Child Survival after Four Years of Intensive Malaria Control. Am J Trop Med Hyg 80: 882-888.

23. Moyou-Somo R, Essomba P, Songue E, Tchoubou NN, Ntambo A, et al. (2013) A public private partnership to fight against malaria along the Chad-Cameroon pipeline corridor: I. Baseline data on socio-anthropological aspects, knowledge, attitudes and practices of the population concerning malaria. BMC Public Health 13: 1023.
24. Oguonu T, Okafor HU, Obu HA (2005) Caregivers's knowledge, attitude and practice on childhood malaria and treatment in urban and rural communities in Enugu, south-east Nigeria. Public Health 119: 409-414.

25. Hlongwana KW, Mabaso ML, Kunene S, Govender D, Maharaj R (2009) Community knowledge, attitudes and practices (KAP) on malaria in Swaziland: A country earmarked for malaria elimination. Malar J 8: 29.

26. Bennett A, Smith SJ, Yambasu S, Jambai A, Alemu W, et al. (2012) Household Possession and Use of Insecticide-Treated Mosquito Nets in Sierra Leone 6 Months after a National Mass-Distribution Campaign. PLoS ONE 7: e37927.

27. Garcia-Basteiro AL, Schwabe C, Aragon C, Baltazar G, Rehman AM, et al (2011) Determinants of bed net use in children under five and household bed net ownership on Bioko Island, Equatorial Guinea. Malar J 10: 179.

28. Maheu-Giroux M, Castro MC (2013) Do malaria vector control measures impact disease-related behaviour and knowledge? Evidence from a large-scale larviciding intervention in Tanzania. Malar J 12: 422.

29. Deressa W, Ali A (2009) Malaria-related perceptions and practices of women with children under the age of five years in rural Ethiopia. BMC Public Health 9: 259.

30. Yimer F, Animut A, Erko B, Mamo H (2015) Past five-year trend, current prevalence and household knowledge, attitude and practice of malaria in Abeshge, south-central Ethiopia. Malar J 14: 230.

31. WHO (2014) The behavioural and social aspects of malaria and its control.

32. Dunyo SK, Afari EA, Koram KA, Ahorlu CK, Abubakar I, et al. (2000) Health centre versus home presumptive diagnosis of malaria in southern Ghana: implications for home-based care policy. Trans R Soc Trop Med Hyg 94: 285-288.

33. Nuwaha F (2002) People's perception of malaria in Mbarara, Uganda. Trop Med Int Health 7: 462-470.

34. Romay-Barja M, Jarrin I, Ncogo P, Nseng G, Sagrado MJ, et al. (2015) RuralUrban Differences in Household Treatment-Seeking Behaviour for Suspected Malaria in Children at Bata District, Equatorial Guinea. PloS One 10: e0135887.

35. Fatungase KO, Amoran OE, Alausa KO (2012) The effect of health education intervention on the home management of malaria among the caregivers of children aged under 5 years in Ogun State, Nigeria. Eur J Med Res 17: 11

36. Romay-Barja M, Cano J, Ncogo P, Nseng G, Santana-Morales MA, et al. (2016) Determinants of delay in malaria care-seeking behaviour for children 15 years and under in Bata district, Equatorial Guinea. Malar J 15: 187.

37. Custodio E, Descalzo MA, Villamor E, Molina L, Sanchez I, et al. (2009) Nutritional and socio-economic factors associated with Plasmodium falciparum infection in children from Equatorial Guinea: results from a nationally representative survey. Malar J 8: 225.

38. Nkuo Akenji TK, Ntonifor NN, Ching JK, Kimbi HK, Ndamukong KN, et al. (2005) Evaluating a malaria intervention strategy using knowledge, practices and coverage surveys in rural Bolifamba, southwest Cameroon. Trans R Soc Trop Med Hyg 99: 325-332. 